\title{
Fatty acid and sensory profiles of Caciocavallo cheese as affected by management system
}

\author{
G. Esposito, ${ }^{*}$ F. Masucci, $\dagger^{1}$ F. Napolitano, $\ddagger$ A. Braghieri,‡ R. Romano, $†$ N. Manzo, $\nmid$ and A. Di Francia $†$ \\ *University of Pretoria, Faculty of Veterinary Sciences, Department of Production Animal Studies, 0110, Onderstepoort, South Africa \\ †Dipartimento di Agraria, Università di Napoli "Federico II," Via Università 100, 80055 Portici (Napoli), Italy \\ $\ddagger$ Scuola di Scienze Agrarie, Forestali, Alimentari ed Ambientali, Università degli Studi della Basilicata, Via dell'Ateneo Lucano 10,85100 Potenza, \\ Italy
}

\section{ABSTRACT}

The effect of season of the year associated with changes in feeding and management system (pasturebased vs. confinement) on milk and cheese fatty acid profile and on sensory properties of Caciocavallo cheese was evaluated on 3 mountain dairy farms. Each farm used a pasture-based feeding system from April to June and from September to October (PS), and a confinement system for the rest of the year (CS). As a consequence of grazing, PS milk showed higher percentages of C18:3, cis-9,trans-11 conjugated linoleic acid, and trans-11 C18:1, and a reduced percentage of C16:0. The fatty acid profile of cheese largely reflected that of the corresponding raw milk from which cheese was made. This led to a significant decrease of atherogenic index in cheeses produced from cows on pasture. Based on sensory analysis, cheese from animals kept on pasture was more yellow and had a lower intensity of butter and smoked odors than did CS cheese. In addition, grazing induced a lower intensity of bitter and a higher intensity of spicy flavors compared with cheese from CS animals. In regard to texture, pasture feeding resulted in higher intensity of friability and graininess. All cheeses performed well in consumer tests; the panel found all samples more than acceptable for overall liking, and for liking according to appearance, taste/flavor, and texture. Overall liking of Caciocavallo cheese, as assessed by slope analysis, was affected primarily by taste/flavor (raw slope $\mathrm{k}=0.88$ ) and texture ( $\mathrm{k}$ $=0.97)$, whereas appearance had a lesser effect $(\mathrm{k}=$ 0.72 ). The acidic and sensory profiles of cheese were well discriminated, with healthier cheeses produced by grazing cows. Therefore, wider use of pasture should be promoted to accentuate this favorable feature. Based on the specific nutritional and sensory characteristics of mountain Caciocavallo cheese, particularly that obtained from grazing animals, efforts should be made to

Received July 25, 2013.

Accepted November 15, 2013.

${ }^{1}$ Corresponding author: felicia.masucci@unina.it indicate the quality of this cheese to the consumer and improve product recognition.

Key words: Caciocavallo cheese quality, feeding system, pasture, management system

\section{INTRODUCTION}

The name "Caciocavallo Silano" designates an Italian "pasta filata" cheese manufactured from raw or heated cow milk, using various types of coagulants and starter cultures, that has been endowed with protected designation of origin (PDO). Its geographical area of production encompasses selected areas of 5 different regions of southern Italy and includes both lowland and mountain zones. A significant part of Caciocavallo PDO cheese is manufactured in mountain semi-extensive dairy farms, where animals are fed preserved forages and concentrates in winter and then switched to pasture in spring.

Upstream factors, in particular rearing system and animal feeding, can influence quality as well as consumer perceptions of dairy products within the same cheese-making chain. In particular, pasture-based feeding systems may provide specific organoleptic qualities to milk products (Agabriel et al., 2004; Coulon et al., 2004; Martin et al., 2005) and portray a healthy image that may offer new marketing opportunities. This healthy image is confirmed by several studies reporting a modified FA profile with an increase in the unsaturated fraction and CLA contents in dairy products derived from grazing systems (Chilliard et al., 2007). Therefore, pasture feeding may represent a useful natural production system providing added value to dairy products.

Studies related to the influence of ruminants' feeding regimen on the sensory properties of cheese are particularly important for typical products (PDO or other origin-promoting instruments) because feeding regimen plays a central role in defining the relationship between typical products and place of origin (Grappin and Coulon, 1996).

The present study aimed to evaluate the effect of season of the year associated with changes in the feeding and management system (pasture based vs. confine- 
ment) on milk and cheese FA profile and on sensory properties (sensory profile and consumer liking) of Caciocavallo cheese from mountain semi-extensive dairies under the usual conditions of farming and management of the herd.

\section{MATERIALS AND METHODS}

Three dairy farms (A, B, C), located in Alta Irpinia, Avellino province, southern Italy $\left(40^{\circ} 54^{\prime} \mathrm{N} 15^{\circ} 25^{\prime} \mathrm{E} ; 900\right.$ $\mathrm{m}$ above sea level), were selected for the study. The farms used pasture as primary source of feeding during the grazing season. Grazing was from the beginning of April until the end of October, with an interruption during July and August due to drought. The animals were kept indoors for the rest of the year and their diets were based only on grains and hay. Although on each farm the treatment consisted of the combination of 3 different elements (season, feeding, and management system), these are referred to hereafter as pasture-based (PS) and confined (CS) management systems for the sake of simplicity.

The 3 farms raised both Italian Friesian and Italian Red Pied cattle, and calving was evenly distributed throughout the year. Each farm produced Caciocavallo cheese exclusively from milk produced on farm. Other relevant farm characteristics are given in Table 1.

\section{Sample Collection Procedure}

The trial was divided into 2 periods of 10 wk each, according to the seasonal pattern of pasture use: the first was from April to June 2009, during the grazing season (PS), and the second was from December 2009 to February 2010, when the animals were kept indoors
(CS). Within each study period, the farms were visited every 2 wk to collect feedstuffs and milk and cheese samples to be used for subsequent analyses, for a total of 5 sampling visits per farm.

Cheese-making process, brining, and ripening methods were recorded once a month to check for variations. The 3 dairies did not change their production processes throughout the experimental period and all used similar cheese-making procedures. Briefly, milk was gently heated $\left(39-40^{\circ} \mathrm{C}\right)$ and coagulated by addition of natural whey culture and commercial kid rennet paste. After approximately $30 \mathrm{~min}$, the coagulum was coarsely cut by hand, heated at $45^{\circ} \mathrm{C}$ for about $2 \mathrm{~h}$, and then reduced to particles of 1.5 to $2 \mathrm{~cm}$ and held at room temperature until the $\mathrm{pH}$ reached 5.30 , a value suitable for stretching. Thereafter, the curd was stretched manually in hot water $\left(80-85^{\circ} \mathrm{C}\right)$ into a typical flask-like shape with a short neck and a small, round top. The cheeses (about $1.5-2.5 \mathrm{~kg}$ each) were cooled in water, salted in brine $(27-30 \% \mathrm{NaCl})$ for about $6 \mathrm{~h} / \mathrm{kg}$, and then dried in a room at a constant temperature $\left(18-22^{\circ} \mathrm{C}\right)$ and relative humidity (60-70\%).

During the grazing season, the 3 herds grazed in corresponding pasture areas, where cages of $2 \times 2 \mathrm{~m}$ were randomly distributed. The number of cages was modified according to pasture sizes and characteristics (6, 4, and 4 for farms A, B, and C, respectively). At each visit, samples of the pasture were cut from ungrazed cages at a height of $5 \mathrm{~cm}$. Proportions of botanical groups (grasses, legumes, and other species) and plant species within these groups were determined. Samples of grains (wheat, oat, and barley meals and their mixture) and hays (clover and natural meadow) fed to the cows in the barn were also collected and the amounts recorded. Two samples (200 mL each) of bulk milk were

Table 1. Characteristics of the 3 farms (A, B, C) under 2 management systems and diets offered in the barn (raw means \pm SD)

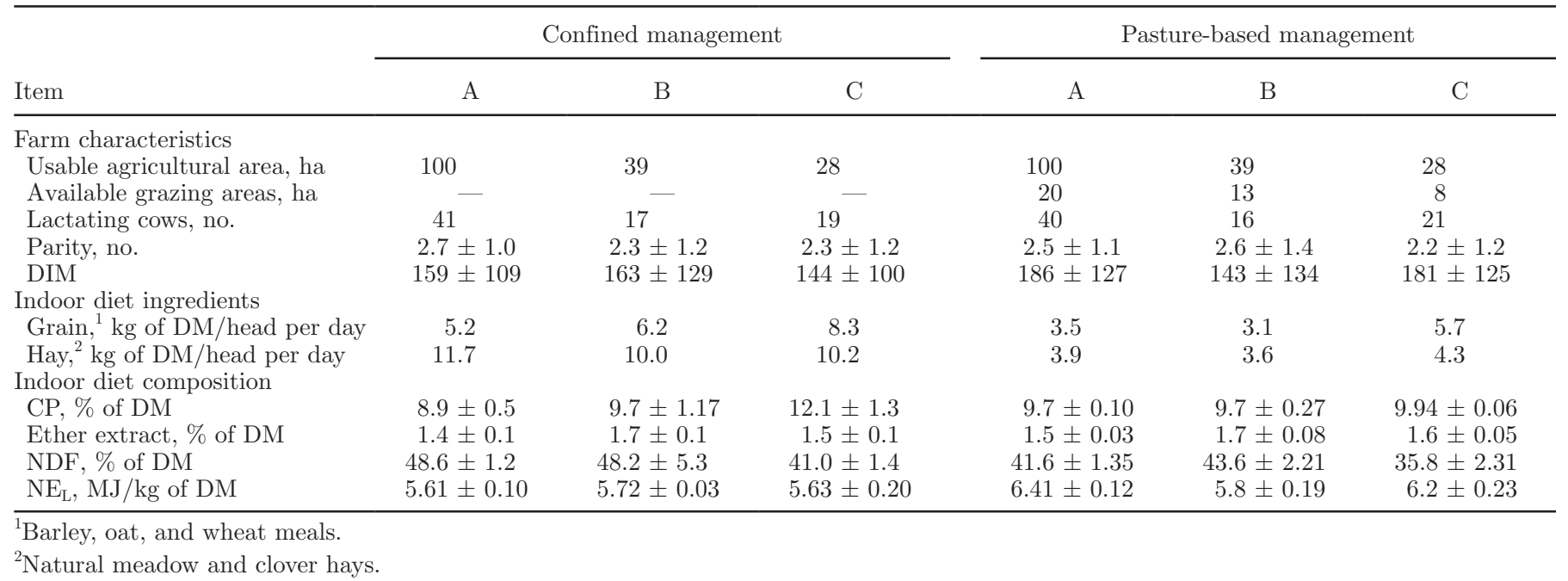


collected in sterile plain jars just before cheese making. One sample was kept refrigerated at $4^{\circ} \mathrm{C}$ and sent to the laboratory for milk composition analyses to be conducted the same day of collection. The other sample was stored at $-20^{\circ} \mathrm{C}$ until milk FA analyses. Moreover, a Caciocavallo cheese (about $1.5 \mathrm{~kg}$ ) from each farm produced from the sampled milk was identified and marked before ripening. These cheeses were stored in farm cheese-aging rooms and were sent to the laboratory for analyses after $90 \mathrm{~d}$.

When the animals were kept indoors, feeds given in the barn and milk and cheeses were sampled as previously described. In this period, feeding was based exclusively on grain meals and hays, locally produced. The rations fed to the cows in the barn were kept constant within each season and the small differences observed in nutritional parameters were due to variations in hay composition (Table 1).

\section{Chemical Analysis of Feeds, Milk, and Cheese, and Color Analysis of Cheese}

The AOAC official methods (AOAC International, 2002) were used to determine DM, ash, ether extract, and CP contents of pasture and feed samples. Neutral detergent fiber inclusive of residual ash was also determined (Van Soest et al., 1991). Milk was analyzed for fat and protein contents by mid-infrared spectrophotometry (MilkoScan FT 6000, Foss Electric, Hillerød, Denmark), for SCC (Fossomatic 90, Foss Electric), and for urea level (CL-10 Plus, Eurochem, Rome, Italy).

Milk FA composition was determined after lipid extraction using the Röse-Gottlieb method, and the trans esterification of triglycerides into the fatty acid methyl esters (FAME) according to the procedures described elsewhere (Romano et al., 2010). The Supelco 37 Component FAME mix (Supelco, Bellefonte, PA) and a CLA isomer mixture (Nu-Chek Prep. Inc. Elysian, MN) were used as external standards. A butter oil reference standard (CRM 164, Community Bureau of Reference, Brussels, Belgium) was routinely used to determine recoveries and correction factors for individual FA. Values $<0.1$ were not quantified. Atherogenic index was calculated according to Ulbricht and Southgate (1991).

From each cheese, a sample of about $200 \mathrm{~g}$ was taken at $2 \mathrm{~cm}$ from the rind and was used to determine chemical composition and to extract fat for FA profile. Moisture was determined by oven drying; quantification of fat, protein, and sodium chloride contents were determined by the Gerber, Kjeldahl, and potentiometric methods, respectively (Fox, 1963; AOAC International, 2002). Extraction of fat from cheese samples was carried out according the Schmidt-Bondzynski-Ratzlaff method with modifications as described by Romano and collaborators (2011). The FA profile of cheese was determined as previously described for milk.

Cheese color was measured, according to CIELAB system, by a Minolta colorimeter CR-300 (illuminant D65, Minolta Camera Co. Ltd., Osaka, Japan) on 3 external and 3 internal nonoverlapping areas of a slice of cheese.

\section{Sensory Analyses of Cheese}

Twelve panelists with a mean age of $25 \mathrm{yr}$ were selected on the basis of their capacity to identify the 4 basic tastes (sourness, sweetness, bitterness, and saltiness; Jellinek, 1985). During preliminary sessions, the assessors, on the basis of available literature (Muir et al., 1995, 1996; Adhikari et al., 2003), developed and then agreed on a consensus list of attributes and their definitions. A single score card with 3 odor, 6 taste, 6 consistency, and 2 color descriptors was compiled, representing the consensus profile of sensory characteristics (Table 2). Subsequently, a reference frame for assessor training was developed, as suggested by Albenzio et al. (2013). Standard reference products specific to each identified attribute were sought. Under the guidance of the panel leader, the assessors determined which of the proposed references were most suitable to represent the previously identified sensory attributes. The identification of reference standards required two 2-h sessions. For a reliable evaluation, at least 2 points of the scale were anchored to the reference material during the panel training.

A quantitative descriptive analysis (QDA) method (Murray et al., 2001) was used to assess the products. In all tests, which were carried out at about $1000 \mathrm{~h}$, cheese cube samples $\left(1 \mathrm{~cm}^{3}\right)$ were served in random order. Attributes were evaluated by rating the samples on 100-mm unstructured lines with anchor points at each end $(0=$ absent and $100=$ very strong $)$. Tests were performed in sensory booths (ISO 8589; ISO, 1988) under red fluorescent lights to mask color differences in the samples, except during the evaluation of cheese color, when only white fluorescent lighting was used. The panelists were not provided with any information regarding the samples to be tasted. Panelists were asked to eat a slice of apple between samples to make the palate conditions similar for each sample. To avoid sensory fatigue due to the number of samples, only 3 samples were evaluated in each session. The interval between samples was approximately $10 \mathrm{~min}$. The panelists evaluated 5 replications of each cheese product. In all, 10 sessions were performed to analyze cheese.

Caciocavallo cheeses were also evaluated for consumer acceptability (Kähkönen et al., 1996). A total of 100 consumers with an average age of $40 \mathrm{yr}$ and bal- 
Table 2. Descriptive attributes and definitions used to evaluate Caciocavallo cheese

\begin{tabular}{ll}
\hline Descriptor & Definition \\
\hline Odor/flavor & Odor/flavor arising from milk at room temperature \\
Milk & Odor/flavor arising from butter at room temperature \\
Butter & Odor/flavor associated with smoked cheese \\
Smoked & Fundamental taste associated with citric acid \\
Taste & Fundamental taste associated with sucrose \\
Sweet & Fundamental taste associated with quinine \\
Bitter & Fundamental taste associated with sodium chloride \\
Salty & Taste associated with hot pepper and involving the whole mouth \\
Spicy & Taste associated with the degree of seasoning \\
Seasoned & Minimum force required to chew cheese sample: the lower the force, the higher the tenderness \\
Texture & Formation of a creamy bulk during mastication \\
Tenderness & Perception of course particles in mouth \\
Creaminess & Force required to remove the mouth coating layer of cheese: the higher the force, the higher the adhesiveness \\
Grainy & Moisture released by the product in the mouth during early mastication (dry: saliva is absorbed by the product; humid: \\
Adhesiveness & liquids are released during mastication). \\
Moisture & Extent to which cheese fragments are increasingly perceived during mastication \\
Friability & Overall uniformity in structure and color \\
Aspect & Overall intensity of yellow color \\
Uniformity &
\end{tabular}

anced for sex participated in the test. Each participant evaluated six $1-\mathrm{cm}^{3}$ cheese samples (corresponding to the 3 farms $\times 2$ management systems) in a controlled sensory analysis laboratory as described for QDA. For each product, consumers expressed an overall liking and liking according to the following sensory inputs: appearance, taste/flavor, and texture. Consumers rated their liking on a 9-point hedonic scale labeled at the left end with "extremely unpleasant" (1), at the right end with "extremely pleasant" (9), and at the central point with "neither pleasant nor unpleasant" (Kähkönen et al., 1996).

\section{Statistical Analyses}

Data were analyzed with SAS software (SAS Institute Inc., Cary, NC). Data on milk and cheese composition were analyzed by a mathematical model that included the effects of management system, farm, and management system $\times$ farm interaction.

The main objective of this work was to compare the 2 seasons of production associated with changes in the feeding and management system. Consequently, even though the effect of farm was often significant, for clarity, data (least squares means) are only expressed by management system and only the most noteworthy differences observed between farms are discussed in the text. For the same reason, the significance of the interaction management system $\times$ farm, found for some milk and cheese FA, was considered negligible and is only briefly discussed. Moreover, to assess the transfer of FA from starter milk to cheese, data of FA composi- tion of milk and cheese were compared separately for each management system and farm by using one-way ANOVA; however, because negligible differences were observed between FA profiles of cheeses and milk, for the sake of brevity, the results of this comparison were omitted.

Sensory profile data were subjected to ANOVA with assessor (12), replication (5), product ( $6=2$ management system $\times 3$ farms), and their interactions as factors. A further ANOVA was performed using management system (2), farm (3), and their interaction as factors. To identify the most liked product, acceptability data were analyzed by ANOVA, using farm, management system, and interaction as factors.

The relationship between overall liking and attribute liking (appearance, taste/flavor, and texture) was analyzed by linear regression analysis according to the following equation:

$$
\text { Overall liking }=\mathrm{k}_{0}+\mathrm{k}_{1} \text { (attribute liking), }
$$

where $\mathrm{k}_{0}$ is the $\mathrm{Y}$ intercept and $\mathrm{k}_{1}$ are the individual slopes relating attribute liking to overall liking (raw slopes). Each consumer served as his/her own control. Significance of this linear equation was evaluated by correlation coefficient (r). Goodness of fit for the individuals was measured by the Pearson coefficient of determination $\left(\mathrm{R}^{2}\right)$, which shows the percentage of variability that can be accounted for by a straight line. Each individual generated 3 raw slopes (i.e., for appearance liking, taste/flavor, liking, texture liking vs. overall liking, respectively). The standard deviation 
Table 3. Botanical and chemical compositions of pasture (LSM \pm SEM) as affected by farm

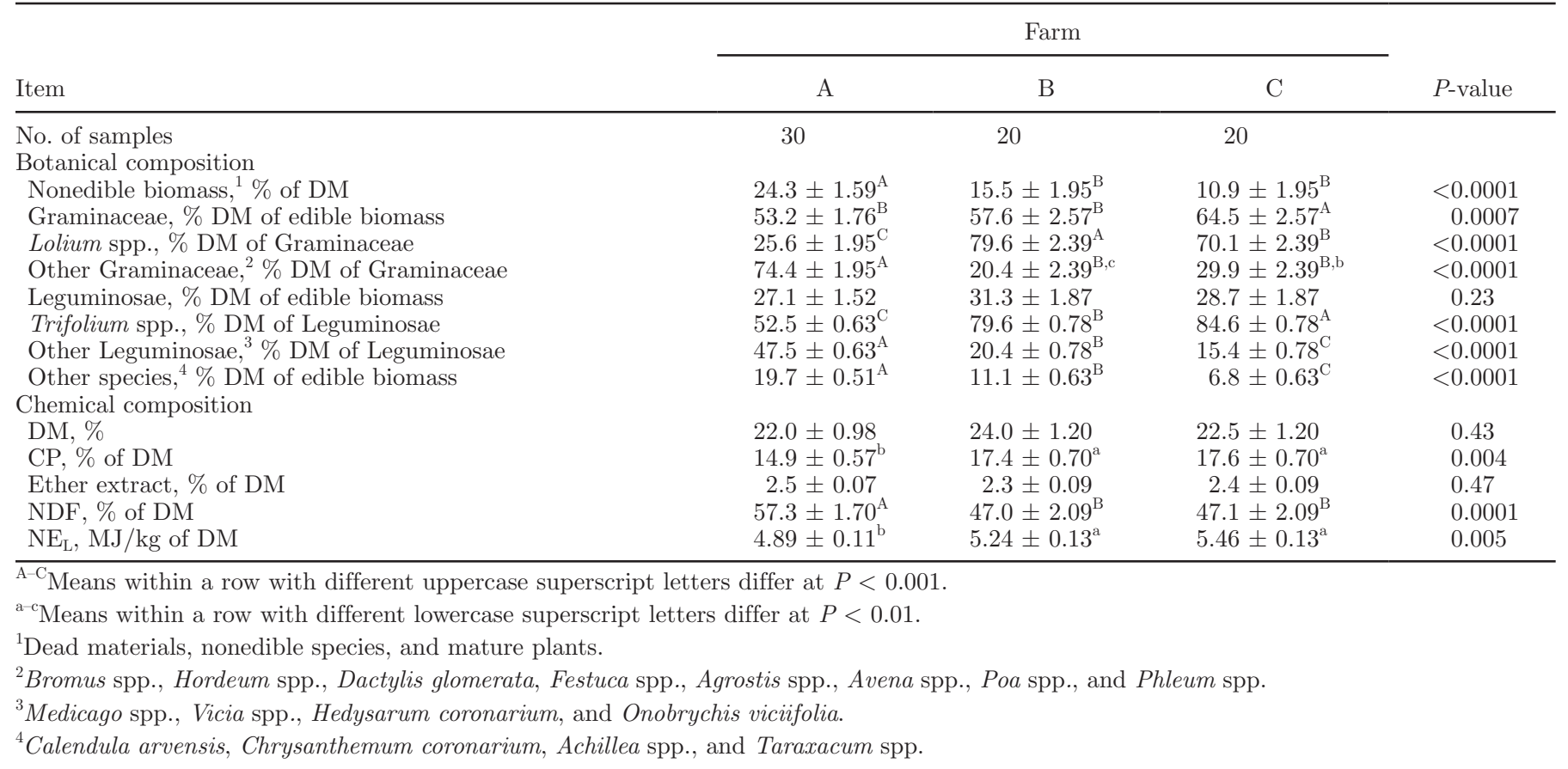

(SD) measures the variability of that individual's raw slopes. The larger the SD of the 3 raw slopes, the more differentially one sensory attribute liking drives overall liking. The smaller the SD of the 3 raw slopes, the more equally the sensory attributes liking drive overall liking.

\section{RESULTS}

\section{Composition of Grazing Pasture}

No agronomic practices were applied in the natural pasture used on farm A. Pastures in farms B and C, in contrast, were sown every 3 to 4 yr with a mixture of annual ryegrass (Lolium spp.) and clovers (Trifolium spp.), and sporadically received nitrogen fertilization. The average botanical and chemical compositions of grazing areas are shown in Table 3. All pasture areas were mostly composed of Graminaceae and Leguminosae, but the natural pasture (farm A) showed higher percentages of nonedible biomass $(P<0.001)$ and other species $(P<0.001)$ compared with the other 2 farms. Moreover, within the Graminaceae and Leguminosae families, the percentages of Lolium spp. $(P<0.001)$ and Trifolium spp. $(P<0.001)$ were lower in natural (farm A) than in sown pastures (farms B and C). As a consequence, natural pasture showed higher percentages $(P<0.001)$ of other Graminaceae and other Leguminosae. The botanical diversity and relative abundance of individual plant species were clearly affected by seeding practices, and possibly by application of fertilizers high in nitrogen, which may be inappropriate for the growth of native and palatable plants (Parfitt et al., 2005).

Chemical and nutritional characteristics of pastures varied between farms depending on botanical composition and plant growth stage (Table 3). In particular, sown pastures (farms B and C) showed higher percentages of $\mathrm{CP}(P<0.01)$, a lower proportion of NDF $(P$ $<0.001)$, and, consequently, a higher energy content $(P<0.01)$ compared with pasture from farm A. No significant differences were observed for fat content.

\section{Milk Traits and Cheese Chemical Composition and Color}

Management system did not affect any milk characteristics (Table 4), including SCC, which were high, possibly because of incorrect milking techniques or the presence of subclinical mastitis.

Table 4 shows that the proximate chemical composition values were within the standards required for Caciocavallo cheese (EC No 1204/03) and the related production roles (e.g., fat content not less than $38 \%$ in DM). Management conditions had a significant effect $(P<0.05)$ only on percent of DM, which was higher in CS cheeses compared with PS cheeses; other chemical parameters were not affected.

In agreement with others (Carpino et al., 2004; Segato et al., 2007; Cozzi et al., 2009) cheeses made from 
Table 4. Milk and cheese characteristics (LSM \pm SEM) as affected by management system

\begin{tabular}{lcccc}
\hline & \multicolumn{2}{c}{ Management system } & & \\
\cline { 2 - 2 } Item & Confined & Pasture-based & SEM & P-value \\
\hline Milk & & & & \\
Yield, kg/head per day & 18.6 & 18.7 & 0.47 & 0.92 \\
Fat, \% & 4.01 & 3.73 & 0.12 & 0.12 \\
Protein, \% & 3.28 & 3.23 & 0.03 & 0.26 \\
Urea, mg/dL & 16.0 & 17.9 & 2.12 & 0.52 \\
SCC, log $_{10}$ cells $/ \mathrm{mL}$ & 5.45 & 5.46 & 0.05 & 0.84 \\
Cheese & & & \\
DM, \% & 71.37 & 69.82 & 0.47 & 0.03 \\
Fat, \% of DM & 47.99 & 47.70 & 0.41 & 0.62 \\
Ash, \% of DM & 4.62 & 4.48 & 0.16 & 0.53 \\
Protein, \% of DM & 32.81 & 33.66 & 0.55 & 0.29 \\
pH & 5.45 & 5.36 & 0.06 & 0.24 \\
NaCl, \% of DM & 1.86 & 1.88 & 0.12 & 0.91 \\
Cheese color & & & \\
L (lightness) & 73.05 & 70.41 & 0.77 & 0.03 \\
a* (red-green color) & -0.38 & 1.33 & 0.18 & $<0.0001$ \\
b* (yellow-blue color) & 20.72 & 26.39 & 0.35 & $<0.0001$ \\
\hline
\end{tabular}

PS milk showed significantly higher redness (a value; $P$ $<0.001$ ) and yellowness (b value; $P<0.001$ ) and, thus, a lower lightness $(\mathrm{L})$ index $(P<0.05)$.

The differences observed between farms for DM $(P$ $<0.01)$, fat $(P<0.001)$, protein $(P<0.001)$, and salt $(P<0.05)$ contents and for color traits $(P<0.001)$ of cheeses (data not shown) may be attributed to several different factors (e.g., genetic type, diet formulation, pasture composition, cheese aging conditions) and are common in cheeses from small dairies and small-batch cheese making.

\section{Milk FA Profile}

The FA composition of milk is shown in Table 5 . Compared with CS milk, the content of de novo $(<16$ C) FA slightly decreased in PS milk, with the exception of $\mathrm{C} 8: 0$ and $\mathrm{C} 13: 0$. A generalized reduction of de novo FA is expected in milk from grazing animals because high levels of dietary PUFA from pasture can compete with de novo FA for esterification in the mammary gland and thus decrease synthesis of short- and medium-chain FA (Palmquist et al., 1993). Moreover, a negative energy balance may occur in lactating cows on pasture, thus reducing the synthesis of short- and medium-chain FA in the mammary gland (Palmquist et al., 1993). The lack of a more marked reduction of de novo FA in PS milk may be attributed to the fact that, on all farms, grazing pasture was integrated with grain meals (Table 1). The supplementation of concentrates, on the one hand, may have helped to cover the cows' needs, but may also have diluted the effect of dietary PUFA on the synthesis of de novo FA. This hypothesis is supported by the study of Bargo et al. (2006), who reported that the provision of concentrate supplementation to grazing animals increased the total content of short- and medium-chain FA in milk.

In agreement with several studies (see Collomb et al., 2006 for a review), FA of mixed origin (C16:0 and C16:1) were always lower in PS milk $(P<0.001)$. Moreover, within the C18 family, PS milk showed higher percentages of C18:0, trans-11 C18:1, C18:3n-3, and cis-9,trans-11 CLA $(P<0.001)$ and lower contents of C18:2n-6 $(P<0.001)$.

The FA composition of CS milk was similar on the 3 farms (data not shown), likely because of the similar winter-feeding regimen used in the farms (i.e., grain meals and hays). The major effect of pasture feeding on trans-11 C18:1 and cis-9,trans-11 CLA concentration (data not shown) was found for milk produced on farm A $(+0.53$ and $+0.96 \mathrm{~g} / 100 \mathrm{~g}$ of FA, respectively for the 2 FA), followed by farms B ( +0.32 and $+0.67 \%$ /weight $)$ and $\mathrm{C}(+0.30$ and $+0.36 \%$ /weight $)$. These results may be due to the different pasture used on the 3 farms (i.e., semi-natural pasture for farm A and sown pasture for farms $\mathrm{B}$ and $\mathrm{C}$ ), in agreement with other on-farm studies (Collomb et al., 2002; Falchero et al., 2010) that reported differences in milk cis-9,trans-11 CLA and C18:3n-3 contents depending on grassland botanical composition. In addition, the higher concentrate supplementation in farm C (Table 1) may have lowered the cis-9,trans-11 CLA and trans-11 C18:1 contents.

Factors other than diet may also play a role in affecting milk FA composition. Kelsey et al. (2003) observed that variation among individuals can influence milk cis-9,trans-11 CLA content, whereas breed, parity, and stage of lactation tend to have a minor effect. An effect of individual cannot be excluded due to the limited size 
Table 5. Milk FA composition as affected by management system (LSM $\pm \mathrm{SEM}$ )

\begin{tabular}{|c|c|c|c|c|}
\hline \multirow[b]{2}{*}{$\mathrm{FA}, \mathrm{g} / 100 \mathrm{~g}$ of $\mathrm{FA}$} & \multicolumn{2}{|c|}{ Management system } & \multirow[b]{2}{*}{ SEM } & \multirow[b]{2}{*}{$P$-value } \\
\hline & Confined & Pasture-based & & \\
\hline $\mathrm{C} 4: 0$ & 2.98 & 2.58 & 0.09 & 0.006 \\
\hline C6:0 & 1.59 & 1.43 & 0.05 & 0.02 \\
\hline $\mathrm{C} 8: 0$ & 0.99 & 1.00 & 0.02 & 0.73 \\
\hline C10:0 & 2.98 & 2.64 & 0.10 & 0.02 \\
\hline C11:0 & 0.29 & 0.25 & 0.02 & 0.04 \\
\hline C12:0 & 3.4 & 3.05 & 0.10 & 0.02 \\
\hline C13:0 & 0.15 & 0.14 & 0.01 & 0.63 \\
\hline C14:0 & 12.1 & 11.6 & 0.21 & 0.11 \\
\hline C14:1 & 0.95 & 0.81 & 0.03 & 0.008 \\
\hline C15:0 & 1.25 & 1.4 & 0.04 & 0.02 \\
\hline C16:0 & 33.26 & 29.26 & 0.03 & $<0.0001$ \\
\hline C16:1 & 2.61 & 2.3 & 0.44 & $<0.0001$ \\
\hline C17:0 & 1.15 & 1.11 & 0.03 & 0.33 \\
\hline C18:0 & 11.21 & 13.69 & 0.28 & $<0.0001$ \\
\hline trans-11 C18:1 & 0.38 & 0.76 & 0.01 & $<0.0001$ \\
\hline C18:1n-9 cis & 20.88 & 23.51 & 0.54 & 0.002 \\
\hline $\mathrm{C} 18: 2 \mathrm{n}-6$ cis & 2.38 & 1.88 & 0.08 & $<0.0001$ \\
\hline C20:0 & 0.16 & 0.22 & 0.01 & 0.0009 \\
\hline $\mathrm{C} 20: 1$ & 0.12 & 0.24 & 0.04 & 0.04 \\
\hline C18:3n-3 & 0.65 & 0.93 & 0.02 & $<0.0001$ \\
\hline cis-9,trans-11 CLA & 0.37 & 1.03 & 0.05 & $<0.0001$ \\
\hline $\mathrm{C} 20: 4 \mathrm{n}-6$ & 0.15 & 0.17 & 0.01 & 0.60 \\
\hline SFA & 71.51 & 68.37 & 0.52 & 0.0003 \\
\hline MUFA & 24.94 & 27.62 & 0.51 & 0.0004 \\
\hline PUFA & 3.55 & 4.01 & 0.09 & 0.002 \\
\hline Atherogenic index ${ }^{1}$ & 2.99 & 2.49 & 0.08 & 0.0002 \\
\hline
\end{tabular}

${ }^{1}[\mathrm{C} 12: 0+(4 \times \mathrm{C} 14: 0)+\mathrm{C} 16: 0] /$ unsaturated FA.

of the herds, but the lack of differences between farms for winter milk cis-9,trans-11 CLA contents (data not shown) support the hypothesis of a major effect of diet.

Overall, under the actual conditions of herd management tested, we could clearly identify the effect of season on milk FA profile in terms of increased percentages of C18:3n-3, cis-9,trans-11 CLA, and trans-11 $\mathrm{C} 18: 1(P<0.001)$ and reduction in $\mathrm{C} 16: 0(P<0.001)$ as a consequence of grazing. The PS season also increased percentage PUFA $(P<0.01)$ and decreased the atherogenic index $(P<0.01)$.

\section{Cheese FA Profile}

The FA composition of cheese is presented in Table 6 . In agreement with others (Buccioni et al., 2010; Revello Chion et al., 2010) reporting a complete transfer of FA from milk to cheese, the FA profile of Caciocavallo cheeses after $90 \mathrm{~d}$ of aging largely reflected the raw milk from which they were made. Thus, most of the discussion previously reported for milk FA profile also applies to cheese, although no effects of season were observed for the majority of de novo $(<16 \mathrm{C}) \mathrm{FA}$. The PS cheeses displayed lower C16:0 contents and higher percentages of C18:1, C18:3n-3, and cis-9,trans-11 CLA. As a consequence, unsaturated FA content increased to the detriment of SFA content in the cheese. This led to a significant decrease in the atherogenic index $(P<$ 0.001 ), resulting in a more favorable FA composition of cheese from grazing cows. Therefore, a wider use of pasture may be promoted in order to accentuate this positive feature.

\section{Cheese Sensory Properties and Consumer Liking}

A main result of the sensory analysis was that the product $\times$ replication and product $\times$ assessor interactions were never significant $(P>0.05)$, indicating a high reliability of the panel performance; that is, the cheeses were not evaluated differently in different replications or by different assessors. The lack of significant interactions allowed us to perform a second ANOVA using management system, farm, and their interaction as main factors. According to this analysis, most of the sensory attributes were affected by management system and farm. Results concerning the effect of management system are reported in Table 7 .

The sensory quality of cheese depends on several factors linked to both the cheese-making technology (milk treatment, starter cultures, clotting process conditions) and the chemical and microbiological characteristics of the raw milk (Martin et al., 2005). Nevertheless, when other factors are similar, some cheese characteristics can be associated with the feeding regimen. In our 
Table 6. Caciocavallo cheese FA composition as affected by management system (LSM \pm SEM)

\begin{tabular}{lcccc}
\hline & \multicolumn{2}{c}{ Management system } & & \\
\cline { 2 - 3 } FA, g/100 g of FA & Confined & Pasture-based & SEM & $P$-value \\
\hline C4:0 & 2.92 & 2.32 & 0.11 & $<0.001$ \\
C6:0 & 1.16 & 1.21 & 0.08 & 0.66 \\
C8:0 & 1.04 & 1.19 & 0.07 & 0.15 \\
C10:0 & 2.72 & 2.51 & 0.11 & 0.16 \\
C11:0 & 0.33 & 0.42 & 0.03 & 0.02 \\
C12:0 & 3.02 & 2.74 & 0.11 & 0.09 \\
C13:0 & 0.21 & 0.16 & 0.04 & 0.40 \\
C14:0 & 12.33 & 11.69 & 0.24 & 0.06 \\
C14:1 & 0.95 & 0.72 & 0.05 & 0.005 \\
C15:0 & 1.24 & 1.49 & 0.05 & $<0.001$ \\
C16:0 & 33.77 & 29.43 & 0.38 & $<0.0001$ \\
C16:1 & 2.55 & 2.46 & 0.09 & 0.48 \\
C17:0 & 1.11 & 1.14 & 0.04 & 0.71 \\
C18:0 & 10.71 & 12.95 & 0.24 & $<0.0001$ \\
trans-11 C18:1 & 0.46 & 0.83 & 0.02 & $<0.0001$ \\
C18:1n-9 cis & 21.49 & 24.00 & 0.50 & 0.002 \\
C18:2n-6 cis & 2.53 & 2.04 & 0.13 & 0.01 \\
C20:1 & 0.16 & 0.22 & 0.01 & 0.0003 \\
C18:3n-3 & 0.13 & 0.22 & 0.04 & 0.16 \\
cis-9, trans-11 CLA & 0.67 & 0.98 & 0.04 & $<0.0001$ \\
C20:4n-6 & 0.36 & 1.12 & 0.04 & $<0.0001$ \\
SFA & 0.16 & 0.17 & 0.01 & 0.07 \\
MUFA & 70.71 & 28.47 & 0.54 & 0.0002 \\
PUFA & 25.58 & 4.31 & 0.51 & $<0.001$ \\
Atherogenic index & 3.71 & 2.43 & 0.13 & 0.003 \\
& 2.94 & & 0.08 & $<0.001$ \\
\hline C1 & & & \\
& & & &
\end{tabular}

${ }^{1}[\mathrm{C} 12: 0+(4 \times \mathrm{C} 14: 0)+\mathrm{C} 16: 0] /$ unsaturated FA.

study, the effect of management system was clear and in agreement with previous studies. Cheese from animals kept on pasture (Table 8) was more yellow in color $(P<0.001)$ and showed a lower intensity of butter $(P$
$<0.05)$ and smoked $(P<0.01)$ odors than cheese from $\mathrm{CS}$ animals. In addition, grazing induced a lower intensity of bitter flavors $(P<0.01)$ and a higher intensity of spicy flavors $(P<0.01)$ compared with cheese from

Table 7. Sensory profile of Caciocavallo cheese as affected by management system (LSM \pm SEM)

\begin{tabular}{llcll}
\hline & \multicolumn{2}{c}{ Management system } & & \\
\cline { 2 - 3 } Item & Confined & Pasture-based & SEM & P-value \\
\hline Appearance & & & & \\
Uniformity & 49.35 & 48.44 & 1.60 & 0.0001 \\
Yellowness & 39.01 & 48.72 & 1.68 & 0.0001 \\
Odor/flavor & & & \\
Milk & 38.17 & 43.43 & 2.30 & 0.10 \\
Butter & 32.88 & 27.00 & 2.07 & 0.05 \\
Smoked & 17.67 & 10.26 & 1.64 & 0.002 \\
Taste & & & \\
Sweet & 29.49 & 34.01 & 2.25 & 0.16 \\
Salty & 24.61 & 28.23 & 1.70 & 0.13 \\
Acid & 16.48 & 14.10 & 1.42 & 0.24 \\
Bitter & 21.32 & 14.59 & 1.57 & 0.003 \\
Spicy & 15.08 & 21.21 & 1.39 & 0.002 \\
Seasoned & 34.45 & 38.49 & 1.67 & 0.003 \\
Texture & & & \\
Tenderness & 47.12 & 49.84 & 2.06 & 0.35 \\
Friability & 24.90 & 36.29 & 1.75 & 0.0001 \\
Grainy & 25.76 & 35.79 & 1.86 & 0.0002 \\
Adhesivity & 34.97 & 38.44 & 1.96 & 0.21 \\
Creaminess & 27.61 & 30.19 & 1.77 & 0.30 \\
Moisture & 36.44 & 33.88 & 1.92 & 0.35 \\
\hline
\end{tabular}


Table 8. Hedonic scores of Caciocavallo cheese as affected by management system (LSM \pm SEM)

\begin{tabular}{lcccc}
\hline & \multicolumn{2}{c}{ Management system } & & \\
\cline { 2 - 3 } Item & Confined & Pasture-based & & SEM \\
\hline Overall liking & 6.80 & 6.63 & 0.10 & $P$-value \\
Appearance & 6.83 & 6.70 & 0.09 & 0.23 \\
Taste/flavor & 6.49 & 6.67 & 0.10 & 0.34 \\
Texture & 6.81 & 6.73 & 0.09 & 0.18 \\
\hline
\end{tabular}

CS animals. In regard to texture, PS cheeses had higher intensities of friability and graininess $(P<0.001)$. Carpino et al. (2004) showed that addition of pasture to a maize silage-based diet resulted in a yellower Caciocavallo Ragusano cheese that was less difficult to fracture and with higher scores for floral and herbaceous odors. Similar results were obtained by Chilliard and Ferlay (2004) and Bonanno et al. (2013).

Milk contains variable amounts of pigments such as carotene, which is present in large proportions in green forage and contributes to the yellow coloration of dairy products (Nozière et al., 2006). The higher yellowness intensity perceived by panelists for PS cheeses confirmed the results concerning instrumental color (Table 4 ), with a higher b index for the same cheeses.

Changes in the texture of PS cheese may be attributed, at least partly, to the corresponding FA composition, which was poorer in SFA such as C14:0 and richer in unsaturated FA such as C18:1 (Table 6) as a consequence of the ingestion of fresh forages. The lower melting point of unsaturated FA may produce softer cheeses (Martin et al., 2005). In addition, some attributes (i.e., spicy and bitter flavors, friability and grainy texture) may be affected by a more intense proteolysis occurring in spring and summer, which, in turn, may contribute to softening cheese during ripening and may have a direct effect on flavor through the production of short peptides and amino acids (McSweeney, 2004).

Table 8 shows the hedonic scores for cheese as affected by management system. All cheeses performed well in the consumer tests; the panel found all samples acceptable, with scores $>5$ (neutral score: neither pleasant nor unpleasant) for overall liking and liking according to appearance, taste/flavor, and texture.

The consumer panel did not perceive any differences for cheeses produced in different farms or management systems. The high temperatures $\left(70-80^{\circ} \mathrm{C}\right)$ reached during the cheese-making process may have flattened any differences perceivable by untrained consumers.

The regression of consumer liking against analytical sensory data can show the most important input driving the acceptance for a specific product (Ward et al., 1999; Moskowitz, 2001). Therefore, the relationship between overall liking and liking of specific sensory inputs (appearance, taste/flavor, and texture) was analyzed by linear regression analysis. Significance of this linear equation was evaluated by correlation coefficient. Thirty percent of consumers showed no significant correlation for all the sensory properties; thus, these consumers were not included in the analysis. Significant differences were observed between appearance and both texture and taste/flavor $(P<0.001$ and $P<0.05$, respectively), whereas no differences were observed between texture and taste/flavor. Therefore, overall liking of Caciocavallo cheese was affected primarily by taste/ flavor [raw slope $(\mathbf{k})=0.88$ ] and texture $(\mathrm{k}=0.97)$, as their raw slopes values were higher. Appearance also affected consumer liking $(\mathrm{k}=0.72)$ but to a lesser extent. Visible characteristics, including visible fat and marbling, are thought to play an important role in orienting consumer preference before consumption for meat and meat products (Fortin et al., 2005), whereas for most other food products, such as cheese, appearance may be less important as a driver of overall liking than taste or texture (Moskowitz and Krieger, 1995).

Based on the sensory characteristics of the products, trained panelists were able to discriminate Caciocavallo cheeses, whereas untrained consumers were not able to detect differences in product. Overall liking of Caciocavallo cheese was primarily affected by taste/flavor and texture and less so by appearance.

\section{CONCLUSIONS}

Under the actual production conditions tested in this study, the FA profiles of Caciocavallo cheese were well discriminated between seasons, with healthier cheeses produced during the season of pasture feeding. Variations in cheese chemical composition and color among farms indicate that these artisanal products are characterized by a high degree of diversity, and the variations that often occur in traditional cheeses produced in small-scale farms should be considered normal. A specific quantitative vocabulary for Caciocavallo sensory analysis was defined, which should be implemented to systematically monitor the quality of cheese produced in the area. Quantitative descriptive analysis detected the effect of grazing on several sensory attributes. Thus, 
based on the specific nutritional and sensory features of mountain Caciocavallo cheese, efforts should be made to signal the quality of this cheese to the consumer and improve product recognition.

\section{ACKNOWLEDGMENTS}

Research was supported by Regione Campania (D.R.D no. 443 06/12/2007). Thanks are due to A. M. Riviezzi (Scuola di Scienze Agrarie, Forestali, Alimentari ed Ambientali, Università degli Studi della Basilicata, Potenza, Italy) for expert technical assistance in sensory analysis, to M. L. Varricchio [Dipartimento di Agraria, Università di Napoli "Federico II," Portici (Napoli), Italy] for help in sample collection and feed analysis, and to R. Di Matteo (Dipartimento di Agraria, Università di Napoli "Federico II") for cheese color analysis.

\section{REFERENCES}

Adhikari, K., H. Heymann, and H. E. Huff. 2003. Textural characteristics of lowfat, fullfat and smoked cheeses: Sensory and instrumental approaches. Food Qual. Prefer. 14:211-218. http://dx.doi. org/10.1016/S0950-3293(02)00067-8.

Agabriel, C., B. Martin, C. Sibra, J. C. Bonnefoy, M. C. Montel, R. Didienne, and S. Hulin. 2004. Effect of dairy production systems on the sensory characteristics of Cantal cheeses: A plantscale study. Anim. Res. 53:221-234. http://dx.doi.org/10.1051/ animres:2004013.

Albenzio, M., A. Santillo, M. Caroprese, A. Braghieri, A. Sevi, and F. Napolitano. 2013. Composition and sensory profiling of probiotic Scamorza ewe milk cheese. J. Dairy Sci. 96:2792-2800. http:// dx.doi.org $/ 10.3168 /$ jds.2012-6273.

AOAC International. 2002. Official Methods of Analysis. 17th ed. AOAC International, Washington, DC.

Bargo, F., J. E. Delahoy, G. F. Schroeder, and L. D. Muller. 2006. Milk fatty acid composition of dairy cows grazing at two pasture allowances and supplemented with different levels and sources of concentrate. Anim. Feed Sci. Technol. 125:17-31. http://dx.doi. org/10.1016/j.anifeedsci.2005.05.010.

Bonanno, A., G. Tornambè, V. Bellina, C. De Pasquale, F. Mazza, G. Maniaci, and A. Di Grigoli. 2013. Effect of farming system and cheese making technology on the physicochemical characteristics, fatty acid profile, and sensory properties of Caciocavallo Palermitano cheese. J. Dairy Sci. 96:710-724. http://dx.doi.org/10.3168/ jds.2012-5973.

Buccioni, A., S. Rapaccini, M. Antongiovanni, S. Minieri, G. Conte, and M. Mele. 2010. Conjugated linoleic acid and C18:1 isomers content in milk fat of sheep and their transfer to Pecorino Toscano cheese. Int. Dairy J. 20:190-194. http://dx.doi.org/10.1016/j. idairyj.2009.10.001.

Carpino, S., S. Mallia, S. La Terra, C. Melilli, G. Licitra, T. E. Acree, D. M. Barbano, and P. J. Van Soest. 2004. Composition and aroma compounds of Ragusano cheese: Native pasture and total mixed rations. J. Dairy Sci. 87:816-830. http://dx.doi.org/10.3168/jds. S0022-0302(04)73226-9.

Chilliard, Y., and A. Ferlay. 2004. Dietary lipids and forages interactions on cow and goat milk fatty acid composition and sensory properties. Reprod. Nutr. Dev. 44:467-492. http://dx.doi. org/10.1051/rnd:2004052.

Chilliard, Y., F. Glasser, A. Ferlay, L. Bernard, J. Rouel, and M. Doreau. 2007. Diet, rumen biohydrogenation and nutritional quality of cow and goat milk fat. Eur. J. Lipid Sci. Technol. 109:828855. http://dx.doi.org/10.1002/ejlt.200700080.
Collomb, M., U. Bütikofer, R. Sieber, B. Jeangros, and J. O. Bosset. 2002. Composition of fatty acids in cow's milk fat produced in the lowlands, mountains and highlands of Switzerland using highresolution gas chromatography. Int. Dairy J. 12:649-659. http:// dx.doi.org/10.1016/S0958-6946(02)00061-4.

Collomb, M., A. Schmid, R. Sieber, D. Wechsler, and E. L. Ryhänen. 2006. Conjugated linoleic acids in milk fat: Variation and physiological effects. Int. Dairy J. 16:1347-1361. http://dx.doi. org/10.1016/j.idairyj.2006.06.021

Coulon, J. B., A. Delacroix-Buchet, B. Martin, and A. Pirisi. 2004. Relationships between ruminant management and sensory characteristics of cheeses: A review. Lait 84:221-241. http://dx.doi. org/10.1051/lait:2004008

Cozzi, G., J. Ferlito, G. Pasini, B. Contiero, and F. Gottardo. 2009. Application of near-infrared spectroscopy as an alternative to chemical and color analysis to discriminate the production chains of Asiago d'Allevo cheese. J. Agric. Food Chem. 57:11449-11454. http://dx.doi.org/10.1021/jf9018905.

Falchero, L., G. Lombardi, A. Gorlier, M. Lonati, M. Odoardi, and A. Cavallero. 2010. Variation in fatty acid composition of milk and cheese from cows grazed on two alpine pastures. Dairy Sci. Technol. 90:657-672. http://dx.doi.org/10.1051/dst/2010035.

Fortin, A., W. M. Robertson, and A. K. W. Tong. 2005. The eating quality of Canadian pork and its relationship with intramuscular fat. Meat Sci. 69:297-305. http://dx.doi.org/10.1016/j.meatsci.2004.07.011

Fox, P. F. 1963. Potentiometric determination of salt in cheese. J. Dairy Sci. 46:744-745. http://dx.doi.org/10.3168/jds.S00220302(63)89134-1.

Grappin, R., and J. B. Coulon. 1996. Terroir, lait et fromage: Éléments de réflexion. Pages 21-28 in 3rd Rencontres Recherches Ruminants, Paris, France. INRA, Paris, France.

ISO (International Organization of Standardization). 1988. Sensory analysis: General guidance for the design of test rooms. ISO 8589 ISO, Geneva, Switzerland.

Jellinek, G. 1985. Sensory Evaluation of Food: Theory and Practice. Ellis Horwood Ltd., Chichester, UK.

Kähkönen, P., H. Tuorila, and H. Rita. 1996. How information enhances acceptability of a low-fat spread. Food Qual. Prefer. 7:87-94. http://dx.doi.org/10.1016/0950-3293(95)00040-2.

Kelsey, J. A., B. A. Corl, R. J. Collier, and D. E. Bauman. 2003. The effect of breed, parity, and stage of lactation on conjugated linoleic acid (CLA) in milk fat from dairy cows. J. Dairy Sci. 86:25882597. http://dx.doi.org/10.3168/jds.S0022-0302(03)73854-5.

Martin, B. I. Verdier-Metz, S. Buchin, C. Hurtaud, and J. B. Coulon. 2005. How do the nature of forages and pasture diversity influence the sensory quality of dairy livestock products? Anim. Sci. 81:205-212. http://dx.doi.org/10.1079/ASC50800205.

McSweeney, P. L. H. 2004. Biochemistry of cheese ripening. Int. J. Dairy Technol. 57:127-144. http://dx.doi.org/10.1111/j.14710307.2004.00147.x.

Moskowitz, H. R. 2001. Margarine: The drivers of liking and image. J. Sens. Stud. 16:53-72. http://dx.doi.org/10.1111/j.1745459X.2001.tb00290.x.

Moskowitz, H. R., and B. Krieger. 1995. The contribution of sensory liking to overall liking: An analysis of six food categories. Food Qual. Prefer. 6:83-90. http://dx.doi.org/10.1016/09503293(95)98552-T.

Muir, D. D., J. M. Banks, and E. A. Hunter. 1996. Sensory properties of cheddar cheese: Effect of starter type and adjunct. Int. Dairy J. 6:407-423. http://dx.doi.org/10.1016/0958-6946(95)00017-8.

Muir, D. D., E. A. Hunter, J. M. Banks, and D. S. Horne. 1995. Sensory properties of hard cheese: Identification of key attributes. Int. Dairy J. 5:157-177. http://dx.doi.org/10.1016/09586946(95)92208-L.

Murray, J., C. Delahunty, and I. Baxter. 2001. Descriptive sensory analysis: past, present and future. Food Res. Int. 34:461-471. http://dx.doi.org/10.1016/S0963-9969(01)00070-9.

Nozière, P., B. Graulet, A. Lucas, B. Martin, P. Grolier, and M. Doreau. 2006. Carotenoids for ruminants: From forages to dairy 
products. Anim. Feed Sci. Technol. 131:418-450. http://dx.doi. org/10.1016/j.anifeedsci.2006.06.018.

Palmquist, D. L., A. Denise Beaulieu, and D. M. Barbano. 1993. Feed and animal factors influencing milk fat composition. J. Dairy Sci. 76:1753-1771. http://dx.doi.org/10.3168/jds.S00220302(93)77508-6.

Parfitt, R. L., G. W. Yeates, D. J. Ross, A. D. Mackay, and P. J. Budding. 2005. Relationships between soil biota, nitrogen and phosphorus availability, and pasture growth under organic and conventional management. Appl. Soil Ecol. 28:1-13. http://dx.doi. org/10.1016/j.apsoil.2004.07.001.

Revello Chion, A., E. Tabacco, D. Giaccone, P. G. Peiretti, G. Battelli, and G. Borreani. 2010. Variation of fatty acid and terpene profiles in mountain milk and "Toma Piemontese" cheese as affected by diet composition in different seasons. Food Chem. 121:393-399. http://dx.doi.org/10.1016/j.foodchem.2009.12.048.

Romano, R., A. Giordano, L. Chianese, F. Addeo, and S. Spagna Musso. 2011. Triacylglycerols, fatty acids and conjugated linoleic acids in Italian Mozzarella di Bufala Campana cheese. J. Food Compost. Anal. 24:244-249. http://dx.doi.org/10.1016/j. jfca.2010.10.004

Romano, R., F. Masucci, A. Giordano, S. Spagna Musso, D. Naviglio, and A. Santini. 2010. Effect of tomato by-products in the diet of Comisana sheep on composition and conjugated linoleic acid content of milk fat. Int. Dairy J. 20:858-862. http://dx.doi. org/10.1016/j.idairyj.2010.05.006.

Segato, S., S. Balzan, C. A. Elia, L. Lignitto, A. Granata, L. Magro, B. Contiero, I. Andrighetto, and E. Novelli. 2007. Effect of period of milk production and ripening on quality traits of Asiago cheese. Ital. J. Anim. Sci. 6:469-471. http://dx.doi.org/10.4081/ ijas.2007.1s.469.

Ulbricht, T. L. V., and D. A. T. Southgate. 1991. Coronary heart disease: Seven dietary factors. Lancet 338:985-992. http://dx.doi org/10.1016/0140-6736(91)91846-M.

Van Soest, P. J., J. B. Robertson, and B. A. Lewis. 1991. Methods for dietary fiber, neutral detergent fiber, and non starch polysaccharides in relation to animal nutrition. J. Dairy Sci. 74:3583-3597.

Ward, C. D. W., C. Stampanoni Koeferli, P. Piccinali Schwegler, D Schaeppi, and L. E. Plemmons. 1999. European strawberry yogurt market analysis with a case study on acceptance drivers for children in Spain using principal component analysis and partial least squares regression. Food Qual. Prefer. 10:387-400. http://dx.doi. org/10.1016/S0950-3293(99)00020-8. 